\title{
1. Introduction: Organizational variety and economic performance
}

\section{Mario Morroni}

\subsection{AN INTERPRETATIVE FRAMEWORK}

This book investigates the heterogeneity of organizational forms of business firms, offering a picture of recent advances in the analysis of different organizational settings adopted by firms in their endeavour to cope with increasing competitive pressure. The chapters of this book are derived from papers first presented at the international workshop on 'Internal Organization, Cooperative Relationships among Firms and Competitiveness', held in Lucca in January 2007. During the meeting a number of stimulating papers animated lively discussions, covering an extensive array of different theoretical and applied themes on the theory of the firm. The present selection contains the papers having direct relevance to the current debate on the emergent variety of organizational forms. ${ }^{1}$ The papers have undergone a substantial revision that reflects the insights and comments from the participants in the workshop and the particular focus of this collection.

Applied studies show a widespread, profound and increasing heterogeneity across firms regarding strategy, organization arrangement and performance. ${ }^{2}$ Different degrees of efficiency seem to bring about relatively persistent profitability differentials among firms, whilst there is no evidence of a link between profitability and the growth rate of firms. As is well known, growth rates tend to differ markedly among firms. ${ }^{3}$ At the basis of inter-firm heterogeneity there is a complex set of links between basic conditions, decision-making mechanisms and organizational settings of the firms. ${ }^{4}$ Efficiency and profitability of the firm depend on the organizational setting which, in turn, is influenced by basic conditions and internal decision making. Naturally, the causal chain also runs in the opposite direction: the competitiveness of a firm contributes to creating the basic conditions that shape internal decision-making processes. These links are outlined in Figure 1.1.

Basic conditions result from the interplay between the environmental conditions that business organizations face and the internal conditions 


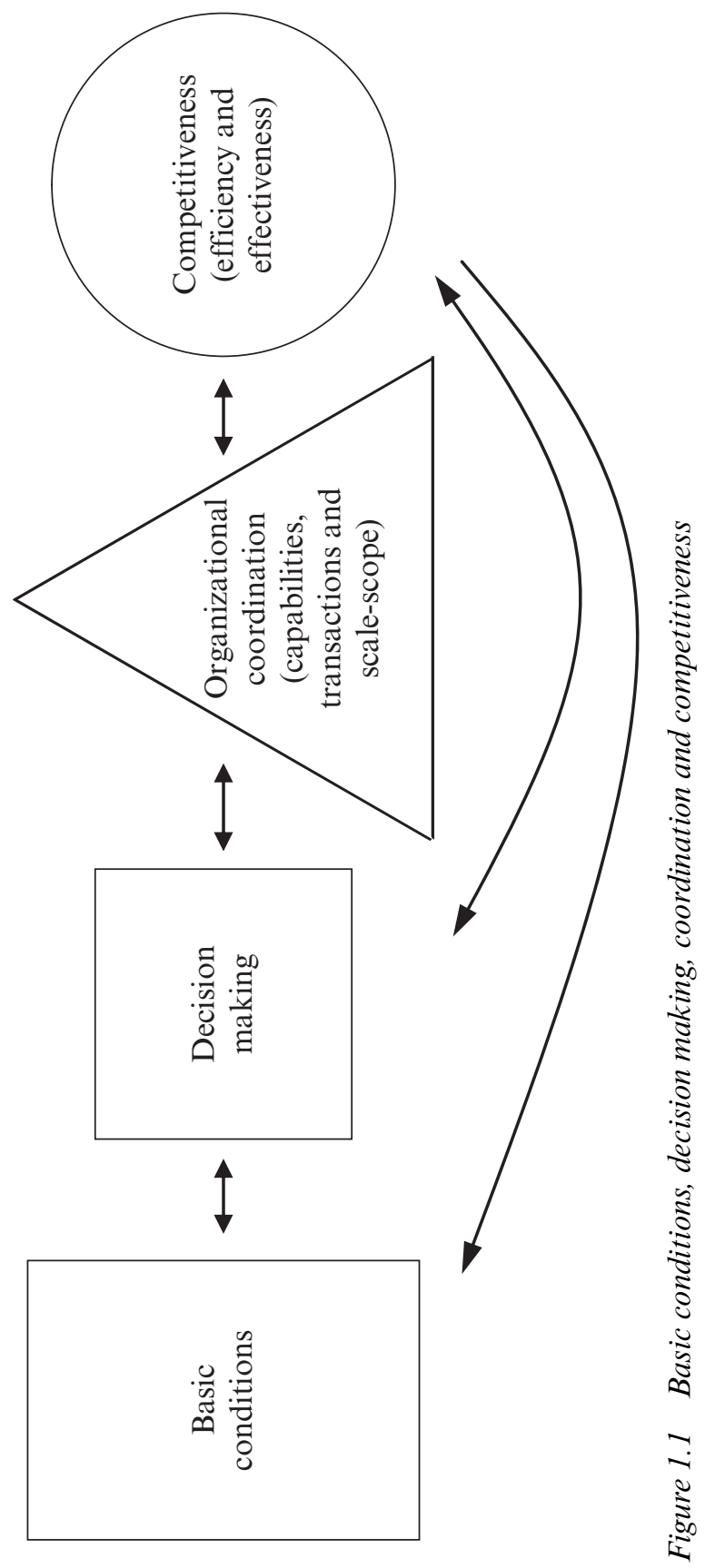


created by business organizations themselves as a result of external constraints and opportunities. Basic conditions are mainly composed of the following interrelated features: (i) attributes of information, knowledge and available techniques and equipment, (ii) individual abilities, motivations and aims, (iii) degree of uncertainty, (iv) structural change and (v) institutional and market conditions.

Among important components that influence decision-making processes within the firm, property structures, control rights, aims of the firm, corporate culture, internal communication systems, incentive design, human resources practices and the kind of rationality (with reference to the level of uncertainty) occupy a salient position.

In industrialized countries a rich tapestry of ownership and governance structures can be observed. Mirella Damiani (Chapter 2 in this book) underlines that different property structures shape a variety of control devices and incentive arrangements across countries. Jackie Krafft and Jaques-Laurent Ravix (Chapter 3) convincingly argue that the adoption of an approach based on a unique and universal set of rules and arrangements neglects the heterogeneity of firms, the diversity of industries and the different stages of their life cycle, as well as the variety of institutional contexts.

Decision-making mechanisms are linked to a multiplicity of organizational practices aiming to pursue efficiency and effectiveness according to the multiplicity of basic conditions. As maintained by Anna Grandori and Santi Furnari (Chapter 4), the heterogeneity of organizational practices arises from the fact that they are the result of specific 'compositions' of different doses of elementary 'organizational elements' - just as different materials are the result of the combination of different qualities and doses of chemical elements.

Decision-making mechanisms and organizational practices affect the organizational coordination between (a) the development of capabilities, (b) the arrangement of transactions and (c) the design of the scale of different processes.

Developing capabilities means finding, interpreting and using knowledge on how to plan, organize and perform production processes. Dynamic capabilities consist of the firm's ability to integrate, build and reconfigure internal and external knowledge in order to address rapidly changing environments. ${ }^{5}$

The arrangement of transactions concerns decisions regarding the relationships with suppliers and customers. Firms that operate in the same sector of activity are often characterized by various levels of vertical integration and different outsourcing relations. This implies the existence of a large variety of hybrid arrangements that shape diverse forms of collaboration among firms. According to the definition provided by Claude 
Ménard (Chapter 5), hybrids are understood as a mode of organization in which significant resources specific to the relationship among partners are shared while ownership remains distinct. Hybrids appear under many different guises: alliances, joint ventures, networks, long-term partnerships, franchising and so on. In recent years firms are no longer outsourcing peripheral activities alone (such as catering, security, distribution); but are instead increasingly outsourcing a wide range of activities encompassing more critical functions that contribute to their competitive position. ${ }^{6}$

In designing the operational scale of each process the firm has to balance the productive capacities of different inputs and intermediate stages. Extension of the boundaries of the firm implies learning how to solve problems of scaling up the processes of production by exploiting the properties of indivisible and complementary production elements (Chandler 1992, p. 84). One observes great variability in firm sizes among and within sectors, whereby the presence of many small firms may coexist with the presence of quite a few very large firms. Yet differences in size tend to persist over time notwithstanding the competition process. In other words, empirical evidence proves there is no tendency towards an optimal size. ${ }^{7}$ Effectively, if we consider the possibility of informational asymmetries, the potential for learning processes within the firm leads to the logical impossibility of determining the firm's optimal size. ${ }^{8}$ With asymmetric information and heterogeneous knowledge, different firms do not bear the same production costs nor do they exhibit the same learning ability. The increase in the whole size of the firm depends on the distinctive features which, in each individual firm, characterize the interaction among the three aspects of the firm's organizational coordination (namely, development of capabilities, arrangement of transactions and design of the scale and scope of processes).

As far as the relationship between the development of capabilities and the growth of the dimension of scale is concerned, applied studies demonstrate that success in innovative activity is a fundamental element that can account for the expansion of fast-growing firms. Not all firms that introduce innovation experience growth but almost all high-growth firms are innovative firms. Coad and Rao (2007) and Hölzl and Friesenbichler (2007) provide ample evidence that learning processes - linked with investments in innovative activity and in product diversification - are of great importance for high-growth firms. ${ }^{9}$ Furthermore, Michie and Sheehan (2005, pp. $448 \mathrm{ff}$.) show that the pursuit of quality and a strategy oriented towards innovation is positively correlated with a strategy of investment in progressive human relation practices that lead to higher levels of commitment and motivation among the members of the firm.

Elsewhere I have attempted to indicate the main conditions under which interaction between the three aspects of organizational coordination (capa- 
bilities, transaction and scale-scope) comes crucially into play (Morroni 2006a, 2007). For the sake of brevity, here it suffices to say that the interaction among these three aspects is intensely influential in determining the organizational boundaries whenever cognitive competence is limited, radical uncertainty is present, ${ }^{10}$ some inputs and processes are indivisible and complementary, and some relevant knowledge is tacit, non-transmittable and characterized by set-up processes with high fixed costs. Under the above conditions, which are becoming increasingly important with the spread of the knowledge-based economy, the growth of the firm can be regarded as a consequence of managerial ability to set a strategy that exploits the mutually reinforcing advantages provided by the organizational coordination of capabilities, transactions and scale of processes, while limiting counteracting forces deriving from errors of strategy that are due to cognitive inertia and myopia, unclear allocation of rights and responsibilities, errors in identifying aims, imprecision in performance measuring, difficulty in focusing incentives, influence activities and problems of internal communication.

Basic conditions and decision-making mechanisms may bear consequences which shape and constrain future decisions of different business organizations. The growth of the firm is the result of a path-dependent process. Initial insignificant circumstances may turn out to be amplified: small causal events in history can thus become important. ${ }^{11}$ Levinthal (1995, p. 26) has shown that even if all organizations face the same environment, they may be led, as a result of these different starting points, to adopt distinct organizational forms. Moreover, at each step, new events and the actions of agents, which may introduce some genuine novelty, could change the direction of path-dependent processes. ${ }^{12}$

With regard to market conditions, heterogeneity in customer preferences - involving such aspects as qualities and sales assistance - may favour the presence of diverse types of firms within narrowly defined industries. ${ }^{13}$ The product of a large mass-production firm is very different, and meets different needs, from the analogous product supplied by a craftsman or by large-scale industrial flexible production. In a given sector of activity the coexistence of several firms of contrasting sizes is not a necessary consequence of the absence of significant economies of scale. It may instead arise from the specific benefits inherent in the small scale of production, which allows a rather different relationship between manufacturers and customers in terms of contractual advantages, flexibility and learning opportunities. Thus in spite of the significant economies of scale that characterize mass production, so highly prized is individual crafting that in many activities handicrafts have never been completely supplanted by cheaper industrial production, having instead survived alongside it. Analogously, just as traditional artisan production was not ousted by the 
rise of mass production in the twentieth century, it seems likely that mass production itself will not be doomed as a result of flexible industrial production (on a large or small scale): rather, the different forms meet quite different needs.

Nevertheless, there is no unequivocal relationship between the pursuit of greater flexibility and the size of production units or firms. In some cases new technology allows a high degree of flexibility in large-scale production, while in other cases it encourages the economic potential of small firms or production units. This results in the presence of a variety of technical and organizational structures.

The instability of demand, the saturation of numerous markets and rising competitive pressures call for diversification. Diversification usually takes place in areas in which the firm's capabilities or resources acquired in the past imply a competitive advantage in carrying out these new activities. Firms usually expand their scope following the development of capabilities in similar activities that need analogous abilities or complementary components or equipment. ${ }^{14}$

The process of growth of the firm takes time because firms have to develop the necessary capabilities both as a means to solve 'problems of scaling up the processes of production' (Chandler 1992, p. 84) and to create a demand for their commodities. For each given scale dimension achieved and technique that can be chosen by the production unit, there are different stages of the development of abilities that facilitate the use of specific machines and equipment. Moreover growth requires expansion of the management team, development of managerial capabilities and effort on the part of existing managers to train new managers. This entails adjustment costs. The pace at which the firm can develop its managerial capabilities sets a limit to its rate of growth (Penrose [1959] 1997, pp. 46-9; Lockett et al. 2007, pp. 5-6).

The innovative success of firms is generally rooted in product diversification. ${ }^{15}$ The growth of the firm is linked to the expansion of its market share within a given market or creation of a new demand, thereby enlarging the market extension. Often the opportunity to exploit potential economies of scale is boosted by the success of a specific product, which is linked to the capacity to create a competitive advantage by exploiting technological opportunities in complementary commodities, matching potential demand and changes in consumer tastes and habits. ${ }^{16}$ When information asymmetries are present, the development of an integrated set of dynamic capabilities through learning becomes an important basis for competitive advantage and therefore "constitutes the foundation for continuing growth' (Chandler 2003, Chapter 1, pp. 7, 15). As argued by Cohendet and Llerena (Chapter 6), the formation of new capabilities is 
made possible by developing or tracking down new abilities and skills which are generated by the ability to utilize outside knowledge (absorptive capacity) and by intensive outside-inside interaction. Product differentiation is sustained by 'knowing communities' within and across firms that create opportunities for diversity and allow experimentation in product configurations. ${ }^{17}$

The achievement of technological progress produces, but at the same time requires, a high degree of variety and heterogeneous abilities among individuals. In economic systems variety springs from the existence of different abilities among individuals and from the fact that individuals are placed in different contexts. This implies potentially different patterns of connections between available bits of information, that is, individuals and organizations can interpret given information in a variety of ways. As Loasby puts it: 'incompleteness and dispersion of knowledge are a constant source of opportunities for creating new knowledge' (1999, p. 149). The ability to learn and innovate varies from one firm to another. The emergence and maintenance of diversity among organizations through innovative activity is favoured by the division of knowledge and is linked to accumulation of different individual abilities and the development of specific capabilities according to specific learning paths. Innovative activity broadens variety. Innovations are produced because firms deliberately seek to differentiate themselves from rivals and adapt to their external environment. Hence variety derives from the purposeful ability to introduce a genuine new idea, and purposefulness itself then plays a crucial role in the selection processes that take place in a social context. ${ }^{18}$ Even more importantly, diversity constitutes a general condition for both the growth of knowledge and profit. ${ }^{19}$ To sum up, there is thus a twoway relationship between innovative activity and heterogeneous abilities: innovative activity may create asymmetric information and heterogeneous abilities, while heterogeneous abilities explain why individuals may have a different propensity or ability to innovate.

The entrepreneurial firm builds a resource base to pursue opportunities. This Schumpeterian creative response generates innovation and diversity in organizational forms and products. ${ }^{20}$ Accordingly, and in the wake of rapid technological change and global competition, firms tend to implement a very wide range of possible governance structures and organizational designs, leading to evolutionary outcomes whose specific traits may take very dissimilar forms in diverse types of firms. Furthermore, the 'entrepreneurial orientation' and the quality of managerial resources vary across firms and over time, ${ }^{21}$ and the inevitably informal nature of the managing of relational agreements and the subjective and discretionary choices by management greatly affect the firm's revealed performance. This subjective element of managerial choice - which is influenced by the various basic 
conditions and the specific manner in which the different stakeholders' interests are weighed in decisions - moulds the specificity of each firm and yields a large variety of outcomes.

\subsection{OUTLINE OF THE BOOK}

The book is divided into two parts. The first addresses theoretical issues on corporate governance, organizational design and cooperative forms among firms, while the second part is dedicated to empirical research on outsourcing forms that are playing an increasing role as a consequence of globalization.

In Chapter 2 Mirella Damiani investigates the effects of diverse governance systems on corporate performance and on the ability to innovate. This chapter shows that various corporate governance systems prevail according to the specificities of the institutional and social environment leading to different forms of capitalism. In addressing the issue of stockholder versus stakeholder-oriented governance systems, Damiani stresses the increasing importance of human capital investments, analysing the complex interaction between labour relations and corporate governance mechanisms. The apparently good functioning of the market for corporate control may destroy long-term relationships and intangible assets, with negative side effects on the ex ante incentives of the potential stakeholders to invest in a specific relation. On the other hand, as Damiani writes in her enlightening chapter, the stakeholder perspective involves problems of incentive systems which may hide, instead of mitigating, managerial misconduct and moral hazard problems. This calls for an attempt to build up institutional complementarities capable of supporting the cooperative governance coalitions, while discouraging collusive alliances.

In the third and closely connected chapter Jackie Krafft and JacquesLaurent Ravix analyse the governance of the knowledge-intensive firm in an industry life cycle approach, highlighting the crucial role of human assets in the growth of knowledge-intensive firms. They show that a mode of governance based on control of the manager's action in the interests of shareholders may not be the optimal solution, since this mode of governance favours short-term choices that may be detrimental to the development of innovation. Rather, within knowledge-intensive firms cooperation and assistance should be the key reference. Krafft and Ravix elaborate a novel interesting perspective on the governance of innovative corporations by defining the notion of 'corporate entrepreneurship' within which managers and investors are collectively involved in the coherence and development of innovative firms. 
In Chapter 4 Anna Grandori and Santi Furnari observe that in dynamic and knowledge-intensive conditions firms are increasingly employing a mixture of organizational elements that are different in kind. They define four classes of organizational elements, distinguishing between market-like, bureaucratic, communitarian and democratic elements. The diversity of possible combinations among those elements is what accounts for the observed 'structural heterogeneity' among large sets of organization forms. Using a chemistry analogy, the chapter outlines a micro-analytic method for analysing organization forms as compounds of elements. The authors define some general 'laws of combinations' among such elements and investigate the effects of these combinations on performance functions under multiple contingencies, developing some formal examples of Boolean algebra applications. It is shown that more that one configuration may be effective under any given circumstance (equifinality). Grandori and Furnari's innovative methodology allows a more precise analysis of the variety of organizational solutions and is supported with references to several applied studies carried out by the two authors themselves, as well as by other scholars' research.

In Chapter 5 Claude Ménard offers a lucid and accurate account of the emergence of the concept of 'hybrid organizations' within transaction costs economics. Hybrid organizations are neither markets nor hierarchies: they are a combination of autonomy and mutual dependence among partners. As persuasively claimed by Ménard, hybrids depend upon the same attributes that explain the other organizational arrangements, that is, the degree of specificity of investments made in the context of the relationship and the uncertainty associated with contractual hazards. Ménard identifies three major dimensions of hybrids: the existence of specific contract laws; the presence of non-contractual modes of adaptation; and the complex nature and role of incentives in a structure in which autonomous holders of property rights develop interdependent activities. Examining systematically the representation of 'hybrids' developed by Oliver Williamson over 30 years, Ménard shows that transaction costs economics provides powerful tools for the understanding of 'hybrid organizations'.

The complex interaction between networks of firms and knowledge communities in a knowledge-intense context is the topic of the last chapter the first part of the book (Chapter 6). In this most interesting contribution Patrick Cohendet and Patrick Llerena explore the role of 'knowledge communities' as informal structures that create specialized knowledge within and across firms. Cohendet and Llerana maintain that the analysis of knowledge communities requires a theory of the firm able to consider simultaneously a transaction perspective, related to division of activities, and a capabilities-based perspective related to division of knowledge. The authors stress the difference between mass production and the information-intense 
production regime of growth. Mass production is characterized by standardized commodities produced by large firms in a relatively stable environment. Since variety in such a context is limited, specialization remains in the private domain of firms, whereas with the new knowledge-based regime of growth the challenge is to deal with increasing variety while maintaining economic efficiency under radical uncertainty. A wide range of products requires the differentiation of skills that are sometimes difficult to build up within the firm. Diversity among firms in their mix of specialized technological knowledge enables them to develop a full range of differentiated products. This new regime calls for cooperation within networks of firms, as cooperation fosters the development of skills in a mutually beneficial way, with each party specializing and agreeing to share learning.

The second part of the book adds significant empirical evidence on the various outsourcing and delocalization activities that, in recent years, have characterized the search for increased competitiveness in many industrial and service sectors.

In Chapter 7 Andreas Reinstaller and Paul Windrum look at the relationship between new internet-based information computer technologies, organizational innovation and outsourcing. They first undertake a useful review of recent empirical studies on the rapid growth in business service outsourcing over the last decade. Then Reinstaller and Windrum develop an original model of organizational innovation in which managers search for an organizational architecture that more effectively integrates the administrative routines of the firm. As part of the innovation process, managers can choose to carry out an administrative activity in-house or to outsource the given activity. A key factor influencing this decision is the relative information costs of organizing routines internally and the information costs associated with setting up and maintaining interfaces with external suppliers. Simulations conducted on this model enable the authors to consider the short- and long-run impact of outsourcing on administration overheads, and on long-term productivity growth. Outsourcing cuts labour costs but simultaneously reduces the scope for internal innovative activity and, hence, may result in being detrimental to long-run productivity gains. If so, there is the danger that managers may become locked into a low productivity growth trajectory. These findings accord well with the empirical data, and provide a salutary warning for managers and policy makers about the potential long-term implications of outsourcing.

In Chapter 8 Massimiliano Mazzanti, Sandro Montresor and Paolo Pini analyse theoretical correlations between outsourcing decisions and outsourcing variables, on the basis of a representative cross-sectional sample of firms of a local production system in Reggio Emilia (Italy). In this chapter the outsourcing firm is considered as a four-fold unit of analysis: 
that is, as an organizational, production, industrial and innovation unit. The authors point out that outsourcing firms of the sample tend to avoid the danger - highlighted by Reinstaller and Windrum in the previous chapter - of being locked into a low productivity growth trajectory because of a myopic pursuit of a mere reduction of costs in the short run. Indeed, in the local production system the general profile of the outsourcing firms appears to be strategic rather than oriented to a short-run perspective, in the sense that tapping into the provider's resources and competences to eventually promote technological innovation seems more relevant than searching for lower costs by contracting out. ${ }^{22}$

The investigation carried out by Rafael Pardo and Ruth Rama in Chapter 9 examines vertical linkages between firms using a statistically representative sample of medium-sized and large companies in the Spanish automobile and electronics industries. Pardo and Rama explore whether the accumulated technological competence of a company is related to outsourcing networks. They conclude that there is ample evidence showing the coexistence of two different situations. For companies outsourcing some of their production, the propensity to network with other firms is positively linked to the technical capital possessed by the firm. In this case social capital and technical capital complement each other. For subcontractors, on the other hand, outsourcing relationships are negatively associated with technical capital possessed by the firm. In this second case social capital seems to be a substitute for the scarce technical capital available to the company. Consistently with the other applied analyses contained in this second part of the book, the variables most closely associated with networking are those indicating development of the internal capabilities of the company.

The last chapter by Carlo Gianelle and Giuseppe Tattara assesses the impact of the delocalization decision on a firm's value added, gross earnings and local employment in the footwear and clothing industries. This chapter presents important evidence based on a survey conducted on a group of final producers located in the north-east of Italy. Gianelle and Tattara consider direct investment, subcontracting and partnerships that materialize as product manufacturing abroad. In the 1980s local footwear and clothing firms reacted to the increased competition in the international markets by outsourcing to domestic subcontractors, while in the 1990s they transferred much of the previous outsourcing abroad, to low labour cost countries, mainly in Eastern Europe and East Asia. The investigation demonstrates that this strategy has been accompanied by a significant increase both in value added per capita and gross profit, giving new competitiveness to this traditional sector of activity.

To sum up, the chapters which are collected in this volume provide a broad range of illustrations of the multifarious nature of the firm. But 
notwithstanding the great variety of organizational solutions, the contributions stress the crucial and increasing role of a reorganization of production that can allow transmission, development and maintenance of productive knowledge in order to sustain a long-run competitive advantage.

\section{NOTES}

1. The theme of the heterogeneity of organizational forms is fascinating and one cannot but agree with Brian Loasby who argued that 'a theory which helps to explain why' firms do not behave in the same way in similar circumstances 'is perhaps to be preferred to one which asserts that they should' (1967, p. 167, quoted in Earl 2002, p. 1).

2. For discussion and bibliographical references on this point, see Dosi (2005, p. 20). On the increasing heterogeneity of Japanese firms since the beginning of the $1990 \mathrm{~s}$, see Lechevalier (2007, pp. 113ff.).

3. The significant heterogeneity of growth rates between firms, within the same sector, is highlighted in Bottazzi et al. (2007); Dosi (2005); Coad and Rao (2007); Baldwin and Gellatly (2006, pp. 7ff.); Hölzl and Friesenbichler (2007). In these applied studies the heavy-tailed nature of the growth rate distribution emerges clearly.

4. This interpretation is based on an analytical framework proposed in Morroni (2006a).

5. Teece et al. ([1997] 1998, p. 204); Loasby (1998, p. 176).

6. On this, see McIvor $(2005$, p. 8). The term outsourcing refers to the sourcing of intermediate goods and services, previously produced internally, from external suppliers.

7. On the wide variability in firm sizes, see Bottazzi et al. (2007); Bottazzi and Secchi (2006); Dosi (2005, pp. 3-4ff.). As argued by Dosi (2005), faced with the evidence that market selection does not seem to lead to an optimal size, the standard production theory centred around U-shaped cost curves loses much of its plausibility.

8. Foss (2002, p. 153). On this logical impossibility, see also Georgescu-Roegen ([1964] 1976, p. 296); Morroni (1992, pp. 141-2, 2006a, Chapter 6); Hodgson (1993, p. 856); Bianchi (1995, p. 187); Penrose ([1959] 1997, p. xii); Marris (2002, pp. 65, 71-2, 75).

9. Moreover, Coad and Rao (2007, p. 28) demonstrate that standard regression analysis on the growth of the mean firm could be misleading because it can be observed that a firm, on average, experiences only modest growth and the reasons for its growth may or may not be related to innovativeness. However, if one focuses on high-growth firms, strong evidence emerges on 'the importance of innovativeness over the entire conditional growth rate distribution'. Cf. Baldwin and Gellatly (2006, p. 25).

10. Lechevalier (2007, p. 128) focuses on the role of uncertainty in heterogeneity across firms. On the relationship between uncertainty and innovative activity, see Morroni (2006b).

11. Hodgson (1998, pp. 36, 47); Dosi and Metcalfe (1991, p. 133).

12. On this, see Antonelli (2004, p. 250); Loasby (2004, p. 271).

13. On the role of heterogeneity of demand and its effect on the industrial structure, see Bonaccorsi and Giuri (2003, pp. 59, 75ff.).

14. Richardson ([1972] 1996, pp. 139-40). Chandler (1992, pp. 83, 96) noticed that unrelated diversification tended quite often to fail in maintaining long term financial performance' because companies that move beyond the barriers created by their 'learned capabilities' could not capture 'economies of scale and scope to obtain lower unit costs'.

15. Fast growing firms are called gazelles by Hölzl and Friesenbichler (2007). These authors provide interesting empirical evidence of the fact that gazelles are more innovative than other firms.

16. See Rosenberg ([1969] 1976, pp. 111-2); Bianchi (1998, pp. 9-11).

17. Rosenberg (2002, p. 36) has called attention to the fact that 'in exploring unknown territory' a 'multiple source of decision making' enhances creative activities and the diversity of options necessary to provide highly differentiated products. 
18. As pointed out in Hodgson and Knudsen (2004, pp. 283-4), artificial selection, particularly important in social contexts where purposefulness is important and acquired characters may be inherited, is consistent with Darwinian principles and can be regarded as a special case of natural selection. On the generation of novelty in the economic process, see Dopfer (1993, pp. 130ff).

19. Loasby (2002, p. 1234); Saviotti (1996, pp. 42, 111).

20. Garnsey (2007) discusses the role of entrepreneurial firms in the generation of diversity.

21. Lockett et al. (2007, pp. 25-6). On the heterogeneity of management practices and productivity, see Bloom and Van Reenen (2007). On firm-specific entrepreneurial knowledge and judgement, see Knight (1921, pp. 311-2); Penrose ([1959] 1997, p. 63); Ricketts (2002, pp. 232ff.).

22. Reinstaller and Windrum's results are consistent with those provided by Michie and Sheehan (2005, pp. 445ff., 461) who demonstrate - on the basis of original data collected from a large sample of publicly quoted UK manufacturing and service sector firms with more than 50 employees - that for companies pursuing quality enhancement or innovation, it is internal or functional flexibility, within an investment in human resource practices, that is linked with such strategies, rather than external or numerical flexibility within a cost-based strategy.

\section{REFERENCES}

Antonelli, C. (2004), 'The system dynamics of localized technological change: ingredients, governance and processes', draft, Dipartimento di Economia, Università di Torino, Italy.

Baldwin, J.R. and G. Gellatly (2006), 'Innovation capabilities: the knowledge capital behind the survival and growth of firms', research paper, Statistics Canada, Micro-economic Analysis Division, Ottawa.

Bianchi, M. (1995), 'Markets and firms: transaction costs versus strategic innovation', Journal of Economic Behaviour and Organization, 28 (2), 183-202.

Bianchi, M. (1998), 'Introduction', in M. Bianchi (ed.), The Active Consumer. Novelty and Surprise in Consumer Choice, London: Routledge, pp. 1-18.

Bloom, N. and J. Van Reenen (2007), 'Measuring and explaining management practices across firms and countries', Quarterly Journal of Economics, 122 (4), 1351408.

Bonaccorsi, A. and P. Giuri (2003), 'Increasing returns and network structure in the evolutionary dynamics of industries', in P.P. Saviotti (ed.), Applied Evolutionary Economics: New Empirical Methods and Simulation Techniques, Cheltenham, UK and Northamptom, MA, USA: Edward Elgar, pp. 50-93.

Bottazzi, G., E. Cefis, G. Dosi and A. Secchi (2007), 'Invariances and diversities in the patterns of industrial evolution: some evidence from Italian manufacturing industries', Small Business Economics, 29 (136), 137-59.

Bottazzi, G. and A. Secchi (2006), 'Explaining the distribution of firm growth rates', RAND Journal of Economics, 37 (2), 235-56.

Chandler, A.D. (1992), 'Organizational capabilities and the economic history of the industrial enterprise', Journal of Economic Perspectives, 6 (3), 79-100.

Chandler, A. (2003), Inventing the Electronic Century: The Epic Story of the Consumer Electronics and Computer Science Industries, New York: The Free Press.

Coad, A. and R. Rao (2007), 'Innovation and firm growth in high-tech sectors: a quantile regression approach', LEM working paper series, Sant'Anna School of Advanced Studies, Pisa, Italy, June. 
Dopfer, K. (1993), 'The generation of novelity in the economic process: an evolutionary concept', in J.C. Dragan, E.K. Seifert and M.C. Demetrescu (eds), Entropy and Bioeconomics, Rome: Nagard, pp. 130-53.

Dosi, G. (2005), 'Statistical regularities in the evolution of industries. A guide through some evidence and challenges for the theory', LEM working paper series, Sant'Anna School of Advanced Studies, Pisa, Italy, June.

Dosi, G. and J.S. Metcalfe (1991), 'On some notions of irreversibility in economics', in P.P. Saviotti and J.S. Metcalfe (eds), Evolutionary Theories of Economic and Technological Change: Present State and Future Prospects, London: Harwood Academic Publisher, pp. 133-59.

Earl, P.E. (2002), Information, Opportunism and Economic Coordination, Cheltenham, UK and Northamptom, MA, USA: Edward Elgar.

Foss, N.J. (2002), 'Edith Penrose: economics and strategic management', in C. Pitelis (ed.), The Growth of the Firm. The Legacy of Edith Penrose, Oxford: Oxford University Press, pp. 147-64.

Garnsey, E. (2007), 'The generation of diversity and the rationale for the entrepreneurial firm', draft, Cambridge: University of Cambridge.

Georgescu-Roegen, N. (1964), 'Measure, quality and optimum scale', in C.R. Rao (ed.), Essays on Econometrics and Planning Presented to Professor P.C. Mahalanobis on His 70th Birthday, Oxford: Pergamon Press, pp. 231-56; repr. in N. Georgescu-Roegen (1976), Energy and Economic Myths, New York: Pergamon Press, pp. 271-96.

Hodgson, G.M. (1993), 'Transaction costs and the evolution of the firm', in C. Pitelis (ed.), Transaction Costs, Markets and Hierarchies, Oxford: Blackwell, pp. 77-100.

Hodgson, G.M. (1998), 'Evolutionary and competence-based theories of firm', Journal of Economic Studies, 25 (1), 25-56.

Hodgson, G.M. and T. Knudsen (2004), 'The firm as an interactor: firms as vehicles for habits and routines', Journal of Evolutionary Economics, 14 (3), 281307.

Hölzl, W. and K. Friesenbichler (2007), 'Are gazelles more innovative than other firms?', Europa Innova, Innovation Watch, preliminary draft, Vienna.

Knight, F.H. (1921), Risk, Uncertainty and Profit, Boston: Houghton.

Lechevalier, S. (2007), 'The diversity of capitalism and heterogeneity of firms - a case study of Japan during the lost decade', Evolutionary and Institutional Economics Review, 4 (1), 113-42.

Levinthal, D.A. (1995), 'Strategic management and the exploration of diversity', in C.A. Montgomery (ed.), Resource-Based and Evolutionary Theories of the Firm: Towards a Synthesis, Boston: Kluwer, pp. 19-42.

Loasby, B. (1967), 'Management economics and the theory of the firm', Journal of Industrial Economics, 15, 165-76; repr. in P.E. Earl (ed.) (1988), Behavioural Economics, 2 vols, Aldershot, UK and Brookfield, USA: Edward Elgar, vol. I, pp. 461-72.

Loasby, B.J. (1998), 'The concept of capabilities', in N.J. Foss and B.J. Loasby (eds), Economic Organization, Capabilities and Co-ordination: Essays in Honour of G. B. Richardson, London: Routledge, pp. 163-82.

Loasby, B.J. (1999), Knowledge, Institutions and Evolution in Economics, London: Routledge.

Loasby, B.J. (2002), 'The evolution of knowledge: beyond the biological model', Research Policy, 31 (8-9), 1227-39.

Loasby, B. (2004), 'Economics after Simon', in M. Augier and J.G. March (eds), 
Models of Man: Essays in Memory of Herbert Simon, Cambridge, MA: MIT Press, pp. 259-78.

Lockett, A., J. Wiklund and P. Davidsson (2007), 'Organic growth and acquisitive growth: re-examining and extending Penrose's growth theory', paper presented at the Academy of Management 2007 Annual Meeting, Philadelphia, USA.

Marris, R. (2002), 'Edith Penrose and economics', in C. Pitelis (ed.), The Growth of the Firm. The Legacy of Edith Penrose, Oxford: Oxford University Press, pp. $61-80$.

McIvor, R. (2005), The Outsourcing Process. Strategies for Evaluation and Management, Cambridge: Cambridge University Press.

Michie, J. and M. Sheehan (2005), 'Business strategy, human resources, labour market flexibility and competitive advantage', International Journal of Human Resource Management, 16 (3), 445-64.

Morroni, M. (1992), Production Process and Technical Change, Cambridge: Cambridge University Press.

Morroni, M. (2006a), Knowledge, Scale and Transactions in the Theory of the Firm, Cambridge: Cambridge University Press.

Morroni, M. (2006b), 'Innovative activity, substantive uncertainty and the theory of the firm', Economia e Politica Industriale, 23 (3), 47-75.

Morroni, M. (2007), 'Complementarities among capability, transaction and scalescope considerations in determining organizational boundaries', Technology Analysis \& Strategic Management, 19 (1), 31-44.

Penrose, E. (1959), The Theory of the Growth of the Firm, 3rd edn, Oxford: Blackwell, with a Foreword by the author 1995, Oxford: Oxford University Press, repr. in 1997.

Richardson, G.B. (1972), 'The organization of industry', The Economic Journal, 82 (327), 883-96, repr. in L. Putterman and R.S. Kroszner (eds) (1996), The Economic Nature of the Firm. A Reader, 2nd edn, Cambridge: Cambridge University Press, pp. 136-45.

Ricketts, M. (2002), The Economics of Business Enterprise. An Introduction to Economic Organization and the Theory of the Firm, 3rd edn, Cheltenham, UK and Northampton, MA, USA: Edward Elgar.

Rosenberg, N. (1969), 'The direction of technological change: inducement mechanisms and focusing devices', Economic Development and Cultural Change, repr. in N. Rosenberg (1976), Perspectives on Technologies, Cambridge: Cambridge University Press, pp. 108-25.

Rosenberg, N. (2002), 'America's university/industry interfaces', draft, Department of Economics, Stanford, California.

Saviotti, P.P. (1996), Technological Evolution, Variety and the Economy, Cheltenham, UK and Brookfield, USA: Edward Elgar.

Teece, D.J., G. Pisano and A. Shuen (1997), 'Dynamic capabilities and strategic management', Strategic Management Journal, 18 (7), 509-33, repr. in D.J. Teece (1998), Strategy, Technology and Public Policy: The Selected Papers of David J. Teece, vol. 2, Cheltenham, UK and Lyme, USA: Edward Elgar, pp. 197-221. 
Mario Morroni - 9781848446120 Downloaded from PubFactory at 04/26/2023 12:57:59PM via free access 